\title{
Cost Change After Initiating Basal Insulin for 6 Months in Patients with Type 2 Diabetes: A Registry Study in China
}

\author{
Dongshan Zhu ${ }^{1,2}$, Xian $\mathrm{Li}^{3}$, Jiachao $\mathrm{Ji}^{3}$, Juming Lü ${ }^{4}$, Weiping Jia ${ }^{5}$, Linong $\mathrm{Ji}^{6}$, Puhong Zhang ${ }^{1,}$ * \\ ${ }^{1}$ Diabetes Research Program, The George Institute for Global Health at Peking University Health Science Center, Beijing, P. R. China \\ ${ }^{2}$ School of Public Health, The University of Queensland, Brisbane, Queensland, Australia \\ ${ }^{3}$ Biostatistics \& Economic Evaluation Program, The George Institute for Global Health at Peking University Health Science Center, Beijing, \\ P. R. China \\ ${ }^{4}$ Department of Endocrinology, The General Hospital of the People's Liberation Army, Beijing, P. R. China \\ ${ }^{5}$ Department of Endocrinology, Shanghai Sixth People's Hospital, Shanghai, P. R. China \\ ${ }^{6}$ Department of Endocrinology and Metabolism, Peking University People's Hospital, Beijing, P. R. China
}

Email address:

dongshan.zhu@uq.net.au (Dongshan Zhu), zpuhong@georgeinstitute.org.cn (Puhong Zhang)

${ }^{*}$ Corresponding author

\section{To cite this article:}

Dongshan Zhu, Xian Li, Jiachao Ji, Juming Lu, Weiping Jia, Linong Ji, Puhong Zhang. Cost Change After Initiating Basal Insulin for 6 Months in Patients with Type 2 Diabetes: A Registry Study in China. International Journal of Diabetes and Endocrinology.

Vol. 4, No. 3, 2019, pp. 62-72. doi: 10.11648/j.ijde.20190403.11

Received: July 18, 2019; Accepted: August 13, 2019; Published: September 3, 2019

\begin{abstract}
This study aims to examine short-term treatment cost changes after initiating basal insulin in insulin naïve patients with type 2 diabetes for 6 months in routine clinical practice. Observational Registry of Basal Insulin Treatment (ORBIT) program is a 6-month, prospective study in China. Patients with type 2 diabetes inadequately controlled (HbA1C $\geq 7 \%)$ by oral antidiabetic drugs (OADs) and willing to initiate basal insulin treatment were enrolled from 209 hospitals of eight geographic regions of China. Type and dose of BI were at the physician's discretion and patients' willingness. Interviews were conducted at baseline, month 3 and month 6. Daily treatment cost (including cost of OAD medication, insulin therapy, self-monitoring of blood glucose and dealing with minor hypoglycemia) of per person before and after adding BIs was evaluated. After adding on Basal insulin, the weighted mean \pm standard deviation (SD) daily treatment cost for insulin-naïve patients with type 2 diabetes increased from $\$ 1.25 \pm \$ 0.74$ (baseline) to $\$ 2.57 \pm \$ 0.68$ at month 6 , a median (Q1, Q3) increase of $1.51(0.38,4.11)$ times over 6 months. The daily treatment cost increased with growing baseline $\mathrm{HbAlc}$ level and prolonged diabetes duration. The reduction in $\mathrm{HbAlc}$ was $2.2 \%$, with minor hypoglycemia increased by 0.68 times/person/year. Insulin cost accounted for the highest proportion (47.9\%) of costs. Our findings suggest adding-on BI therapy may increase the daily treatment cost by 1.5 times at 6 months. Early initiation of BI therapy may provide an opportunity to achieve treatment goals with low cost and low risk of hypoglycemia.
\end{abstract}

Keywords: Basal Insulin, Cost, Type 2 Diabetes

\section{Introduction}

Type 2 diabetes mellitus (T2DM) is a major public health challenge in China. With the largest population with T2DM in the world — estimated at 98.4 million people in 2013 [1] — the prevalence of T2DM in China has risen dramatically over the decades [2]. Nationally representative samples reported a prevalence rate of $9.7 \%$ in 2007 [3] and 2010 [4], based on 1999 World Health Organization diagnostic criteria [5].
Moreover, only approximately $25 \%$ of patients with T2DM in China have access to treatment, with only $39.7 \%$ of those achieving adequate glycemic control [4]. Poor glycemic control and the consequential development of complications associated with T2DM increase treatment costs.

As T2DM progresses, introduction of insulin becomes imperative to maintain adequate glucose control [6, 7]. Guidelines on diabetes management recommend the addition of basal insulin (BI) in combination with second- or third-line 
of antihyperglycemic therapy and use of BI as an initial treatment in patients with inadequate glucose control with oral antidiabetic drugs (OADs) [8-12].

The therapeutic choices for BI include neutral protamine hagedorn (NPH) insulin and the long-acting analogs, insulin glargine and insulin detemir. Clinical trials [13-17] and observational [18-22] studies have evaluated the efficacy and effectiveness of BI therapies in T2DM patients, and shown that when added to existing OADs, all these forms of BIs can effectively control glucose, although BI analogs have demonstrated lower risk of hypoglycemia compared with NPH insulin.

Besides effectiveness and safety, the acceptability of a certain therapy also depends on the influence of that therapy on costs following initiation of it, which relates to affordability. Previous studies on the costs of BIs, either in clinical trials or observational studies (prospective or retrospective cohort) [23-27], emphasized on evaluating the long-term cost-effectiveness (through the index of cost/quality-adjusted life-years [QALYs]) by using diabetes models, such as the Center for Outcomes Research (CORE) model [28, 29]. Few studies have evaluated short-term change in treatment cost caused by regimen conversion from insulin-naïve therapy to add-on insulin therapy. Thus, the treatment cost changes during this conversion is unknown. In the real world, types and dose of BIs were initiated based on physicians' judgment and patients' preference. This large-scale observational study aimed to evaluate the short-term cost changes for patients undergoing a conversion from OAD-only regimen (insulin-naïve patients) to add-on insulin therapy in routine clinical practice.

\section{Materials and Methods}

\subsection{Study Design}

ORBIT was a 6-month, multicenter, prospective registry study conducted in China. A nationally representative sample of patients with established T2DM was enrolled at hospitals representative of eight geographic regions and two hospital tiers at secondary (county or district) and tertiary (provincial or national) levels. Insulin-naïve patients with T2DM aged 18-80 years inadequately controlled with OADs (glycated hemoglobin $[\mathrm{HbAlc}] \geq 7 \%, 53 \mathrm{mmol} / \mathrm{mol}$ ) and willing to accept BI treatment were consecutively enrolled by their physicians from the end of 2011 to June 2013, in same number of secondary and tertiary hospitals all over China. The type and dose of BI were prescribed based on the physicians' judgment and patients' preferences.

For each participant, the costs were investigated before the initiation of BI (visit 0 ), immediately after the initiation of BI (visit 1), at mid-term (3 months, visit 2), and at the end of the study (6 months, visit 3 ). Patients were asked to bring their routine medications for taking for interviewers to check during investigation. Types and doses of daily consumed OADs and insulin, number of needles used for injection per day, self-reported frequency of SMBG (self-monitoring of blood glucose) and minor hypoglycemia in the previous one month were documented for each patient. According to the American Diabetes Association (ADA) recommendations [11], minor hypoglycemia episodes included documented symptomatic, asymptomatic, probable symptomatic, or pseudo-hypoglycemia. The frequency of severe hypoglycemia was extremely low, with 0.05 episodes/person-year in visit 1 and 0.03 episodes/person-year at visit 3. Given the short observation period, it was not included in this cost analyses [11].

The protocol was approved by the Institutional Review Board (IRB) of Peking University, and when necessary, by local IRBs. Further details on the study design and baseline characteristics are available in a previous article [30].

\subsection{Cost Definition and Calculations}

Diabetes treatment costs in this study consisted of cost of OAD medication, insulin therapy (including needles used for injection), SMBG (including blood glucose testing strips and lancets), and cost to deal with minor hypoglycemia.

\subsubsection{Definition of Unit Cost}

a) Unit cost of insulin: Based on the sale price of a certain insulin in the hospital, the unit cost of insulin = the sale price of insulin (\$)/the total dose of a single commodity (International unit, IU).

b) Unit cost of OADs: Based on the sale price of a certain $\mathrm{OAD}$ in the hospital, the unit cost of an $\mathrm{OAD}=$ the sale price of an $\mathrm{OAD}(\$) /$ the total dose of a single commodity (mg).

c) Unit cost of needles used for injection, blood glucose testing strips and lancets were based on the sale price for a single unit in each hospital.

The average cost for dealing with each minor hypoglycemia episode was 2.4 Chinese yuan (CNY) [31].

\subsubsection{Cost Calculations}

Daily treatment cost was evaluated in this study. For each patient, the daily cost was calculated as follows:

a) Daily cost of OADs medication $=\sum_{i=1}^{k}$ Unit cost of $O A D_{i} \times O A D_{i}$ dose used per day, where $\mathrm{k}$ is the number of types of OAD;

b) Daily cost of insulin therapy

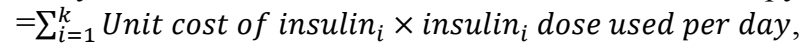
where $\mathrm{k}$ is the number of types of insulin;

c) Daily cost of needles $=$ (Number of needles used in past 7 days $\times$ unit cost of needle) $/ 7$.

d) Daily cost of SMBG $=$ Frequency of SMBG in past 30 days $\times$ (unit cost of strips + unit cost of lancets) $/ 30$;

e) Daily cost of hypoglycemia event $=$ (Frequency of hypoglycemia in past 30 days $\times$ average cost of hypoglycemia treatment)/30;

f) Total daily treatment cost for each patient= Daily cost of OADs medication + Daily cost of insulin therapy + Daily cost of needles +Daily cost of SMBG + Daily cost of hypoglycemia event;

g) Daily treatment cost change from visit 0 to visit 3 for each patient $=$ Total daily treatment cost at visit 3 - Total 
daily treatment cost at visit 0 ;

h) Times of cost increase for each patient= Daily treatment cost change from visit 0 to visit 3 / Total daily treatment cost at visit 0 .

\subsection{Statistical Methods}

Descriptive statistics were used in analyses. Characteristics of overall patients and patients in individual region were described. Daily treatment cost change from visit 0 to visit 3 and times of cost increase were described in each region. The weighted mean of overall cost increase from visit 0 to visit 3 , and weighted overall times of cost increase were calculated from the value of each region. The weight for each region was calculated by using following process. Firstly, according to the prevalence [32] of T2DM and population of each province [33], the number of patients with T2DM in each province was calculated. Then, the total number of patients with T2DM in each region was calculated by gathering the patients' number in each province included in that region. Third, the weight of each region was calculated by using the number of patients in that region divided by the total number of patients in eight regions. After calculation, the weights of eight regions were: Southwest (0.10), Northwest (0.04), Mid-Yangtze River (0.16), Mid-Yellow River (0.15), South Coast (0.13), East Coast (0.12), North Coast (0.20), Northeast (0.10). Detailed calculation process was showed in Table 5.

Weighted mean of cost increase and weighted times of cost increases were also described in subgroups such as region, hospital tier, source of patients, baseline HbAlc level and diabetes duration etc. Changes in the factors related to costs, including OAD number, insulin dose, SMBG and hypoglycemia frequency were described from visit 0 to visit 3 . Cost proportion of each item at each visit were also described.

For continuous variables, a normality test was performed. Continuous variables with normal distribution were presented as mean $\pm \mathrm{SD}$ values. Continuous variables for skewed distribution, commonly treated as normal data in most studies, were also reported as mean $\pm \mathrm{SD}$, while other variables were reported as median (Q1, Q3). Discrete variables were presented as $\mathrm{n}(\%)$. All costs were presented in US dollar (\$).

\section{Results}

\subsection{Baseline Characteristics}

18,995 patients qualified for recruitment. Detailed baseline characteristics at baseline have been described in a different publication [30]. Of the 18,995 participants, 16,341 completed the 6-month follow-up. The mean age was $55.4 \pm 10.3$ (mean $\pm \mathrm{SD})$ years, and $52.8 \%$ of the participants were men; the mean body weight was $67.4 \pm 11.8 \mathrm{~kg}$; the mean $\mathrm{HbA1c}$ and fasting plasma glucose (FPG) were $81(9.6 \%) \pm 21.9$ $\mathrm{mmol} / \mathrm{mol}$ and $11.6 \pm 4.0 \mathrm{mmol} / \mathrm{L}$ at baseline, respectively; and the mean duration of diabetes was $6.5 \pm 5.3$ years. Percentage of patients in different subgroups in overall and eight geographical regions were demonstrated in Table 6 .

\subsection{Daily Treatment Cost in Eight Regions}

Overall, before initiation of BIs, the weighted mean of daily treatment cost for insulin-naïve T2DM patients was $\$ 1.25 \pm$ $\$ 0.74$, which increased to $\$ 2.29 \pm \$ 0.51$ following prescription of Bis and $\$ 2.57 \pm \$ 0.68$ after 6 months, a median (Q1, Q3) increase of $1.51(0.38,4.11)$ times over 6 months. The daily treatment cost change and times of cost increase varied in regions (Table 1). Clinical outcomes at month 6 in overall and eight regions were listed in Table 7 . The overall reduction in $\mathrm{HbAlc}$ was $2.2 \%$. The frequency of minor hypoglycemia increased by 0.68 times/person/year, with a slight increase in body weight.

Table 1. Daily treatment cost at each visit, daily treatment cost change and times of cost increase at month 6 in total and 8 regions.

\begin{tabular}{|c|c|c|c|c|c|c|c|c|}
\hline \multirow[t]{2}{*}{ Regions } & \multicolumn{2}{|c|}{ Treatment cost at v0 } & \multicolumn{2}{|c|}{ Treatment cost at v1 } & \multicolumn{2}{|c|}{ Treatment cost at $v 3$} & \multirow{2}{*}{$\begin{array}{l}\text { Treatment cost } \\
\text { change (v3-v0) } \\
\text { Mean } \pm \text { SD (\$) }\end{array}$} & \multirow{2}{*}{$\begin{array}{l}\text { Times of cost increase } \\
\text { at } 6 \text { monthsł: } \\
\text { Median }(Q 1, Q 3)\end{array}$} \\
\hline & $\mathbf{N}$ & Mean \pm SD (\$) & $\mathbf{N}$ & Mean \pm SD (\$) & $\mathbf{N}$ & Mean \pm SD (\$) & & \\
\hline North coast & 3273 & $1.41 \pm 1.96$ & 3273 & $2.46 \pm 1.56$ & 2917 & $2.82 \pm 1.70$ & $1.45 \pm 2.21$ & $1.47(0.38,4.18)$ \\
\hline Yangtze River & 3018 & $1.18 \pm 2.00$ & 3018 & $2.41 \pm 1.31$ & 2605 & $2.56 \pm 2.49$ & $1.40 \pm 2.02$ & $1.51(0.44,4.29)$ \\
\hline Southwest & 2913 & $1.33 \pm 2.25$ & 2913 & $2.01 \pm 1.31$ & 2175 & $2.46 \pm 1.78$ & $1.11 \pm 2.66$ & $1.45(0.26,4.02)$ \\
\hline Yellow River & 2830 & $0.89 \pm 1.25$ & 2830 & $1.67 \pm 1.16$ & 2628 & $1.88 \pm 1.16$ & $1.02 \pm 1.39$ & $1.59(0.32,4.46)$ \\
\hline East coast & 2267 & $1.38 \pm 2.16$ & 2267 & $2.43 \pm 1.36$ & 1978 & $2.86 \pm 1.77$ & $1.49 \pm 2.49$ & $1.46(0.45,3.35)$ \\
\hline South coast & 1987 & $1.42 \pm 2.21$ & 1987 & $2.53 \pm 1.27$ & 1620 & $2.77 \pm 1.86$ & $1.32 \pm 2.47$ & $1.07(0.22,3.22)$ \\
\hline Northeast & 1670 & $1.09 \pm 2.51$ & 1670 & $2.68 \pm 1.37$ & 1435 & $2.82 \pm 1.62$ & $1.82 \pm 1.96$ & $2.41(0.81,5.67)$ \\
\hline Northwest & 1037 & $1.24 \pm 1.98$ & 1037 & $2.45 \pm 1.05$ & 977 & $2.60 \pm 1.11$ & $1.37 \pm 2.19$ & $1.38(0.48,3.39)$ \\
\hline Total $^{\dagger}$ & 18995 & $1.25 \pm 0.74$ & 18995 & $2.29 \pm 0.51$ & 16335 & $2.57 \pm 0.68$ & $1.35 \pm 0.80$ & $1.51(0.38,4.11)$ \\
\hline
\end{tabular}

${ }^{\dagger}$ For the total values, weighted means of daily treatment cost for each visit and weighted medians for times of cost increase at month 6 were calculated. The weights for each region were: Southwest (0.10), Northwest (0.04), Mid-Yangtze River (0.16), Mid-Yellow River (0.15), South Coast (0.13), East Coast (0.12), North Coast (0.20), Northeast (0.10). v0, visit 0- Before initiation of BI; v1, visit 1- Immediately after the initiation of BI; v3, visit 3- End of the study at month 6; SD, standard deviation; Q1, 25th percentile; Q3, 75th percentile.

${ }^{\ddagger}$ Times of cost increase $=($ Treatment cost change $) /$ Treatment cost at v0.

\subsection{Daily Treatment Cost in Subgroups}

Patients in tertiary hospital, in-patients had higher daily treatment cost increase than patients in secondary ( $\$ 1.42$ vs. $\$ 1.27, p<0.05)$ and out-patients $(\$ 1.38$ vs. $\$ 1.32, P<0.05)$ respectively. Treatment cost change increased with the growing of baseline HbA1c level (Figure 1A) and prolonged diabetes duration (Figure 1B). Patients with insulin glargine $(1.49 \pm 2.09)$ or detemir $(1.66 \pm 2.54)$ had higher treatment 
cost change than those with NPH insulin $(0.56 \pm 2.14)$. than those who had used two or more OADs (Table 2). Patients using only one OAD had the highest cost increase

(A)

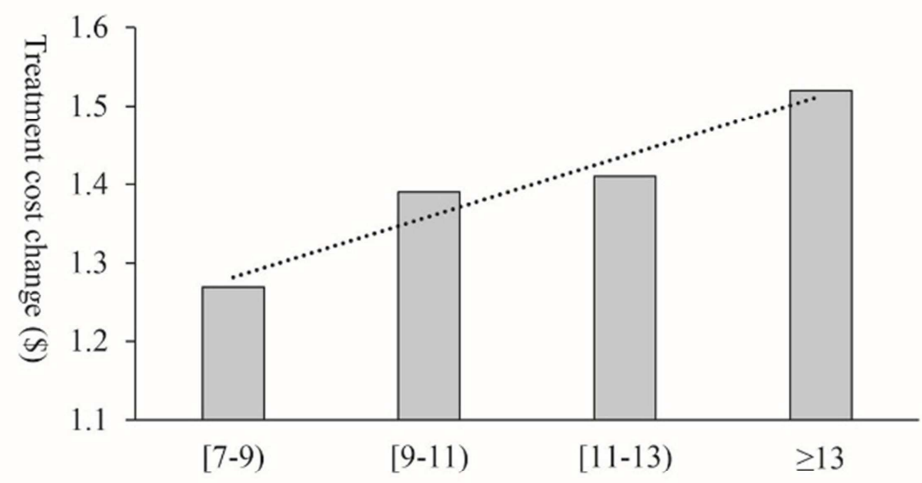

$\mathrm{HbAlc}$ level at baseline (\%)

(B)

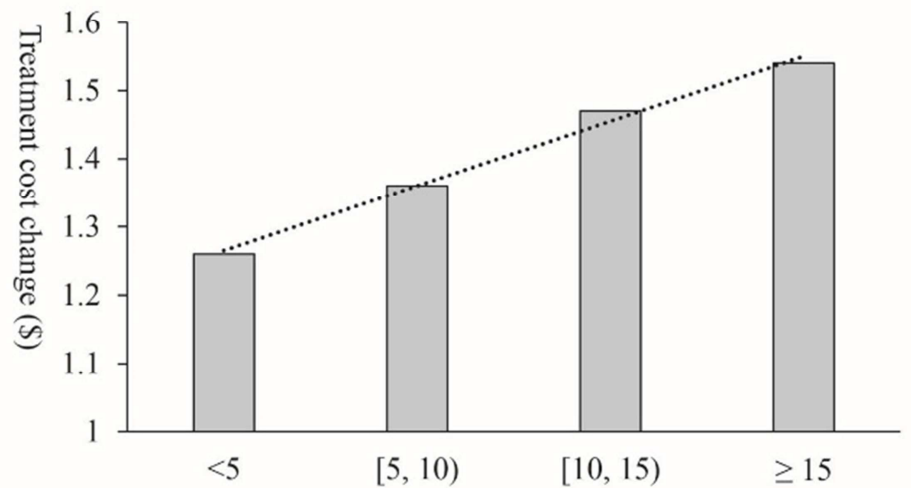

Diabetes duration at baseline (years)

Figure 1. Association between treatment cost change at month 6 and (A) baseline HbA1c (\%) level, (B) baseline diabetes duration (years).

Table 2. Daily treatment cost at each visit, daily treatment cost change and times of cost increase in various subgroups ${ }^{\dagger}$.

\begin{tabular}{|c|c|c|c|c|c|c|c|}
\hline \multirow[b]{2}{*}{ Group variable } & \multicolumn{2}{|c|}{ Treatment cost at v0 } & \multirow{2}{*}{$\begin{array}{l}\text { Treatment cost at v1 } \\
\text { Mean } \pm \text { SD }(\$)\end{array}$} & \multicolumn{2}{|c|}{ Treatment cost at v3 } & \multirow{2}{*}{$\begin{array}{l}\text { Treatment cost } \\
\text { change (v3-v0) } \\
(\$)\end{array}$} & \multirow{2}{*}{$\begin{array}{l}\text { Times of cost increase at } 6 \\
\text { months } \div \text {, Median (Q1, } \\
\text { Q3) }\end{array}$} \\
\hline & $\mathbf{N}$ & Mean \pm SD (\$) & & $\mathbf{N}$ & Mean \pm SD (\$) & & \\
\hline Total & 18,995 & $1.25 \pm 0.74$ & $2.29 \pm 0.51$ & 16335 & $2.57 \pm 0.68$ & $1.35 \pm 0.80$ & $1.51(0.38,4.11)$ \\
\hline \multicolumn{8}{|l|}{ Hospital level } \\
\hline Secondary & 9443 & $1.12 \pm 2.10$ & $2.10 \pm 1.41$ & 8421 & $2.39 \pm 1.87$ & $1.27 \pm 2.10$ & $1.55(0.4,4.35)$ \\
\hline Tertiary & 9552 & $1.36 \pm 1.98$ & $2.48 \pm 1.29$ & 7914 & $2.75 \pm 1.73$ & $1.42 \pm 2.28$ & $1.45(0.36,3.85)$ \\
\hline \multicolumn{8}{|l|}{ Age (years) } \\
\hline$[40,50)$ & 4253 & $1.24 \pm 2.57$ & $2.27 \pm 1.25$ & 3647 & $2.52 \pm 2.22$ & $1.27 \pm 2.73$ & $1.57(0.37,4.21)$ \\
\hline$[50,60)$ & 6541 & $1.22 \pm 1.88$ & $2.30 \pm 1.42$ & 5675 & $2.58 \pm 1.62$ & $1.38 \pm 2.00$ & $1.51(0.40,4.13)$ \\
\hline$\geq 60$ & 6924 & $1.28 \pm 1.75$ & $2.28 \pm 1.35$ & 5916 & $2.60 \pm 1.67$ & $1.34 \pm 2.01$ & $1.42(0.36,3.81)$ \\
\hline \multicolumn{8}{|l|}{ Gender } \\
\hline Male & 9968 & $1.24 \pm 2.01$ & $2.35 \pm 1.35$ & 8623 & $2.62 \pm 1.90$ & $1.38 \pm 2.24$ & $1.55(0.38,4.16)$ \\
\hline Female & 9027 & $1.24 \pm 2.08$ & $2.21 \pm 1.38$ & 7712 & $2.51 \pm 1.71$ & $1.31 \pm 2.14$ & $1.46(0.38,4.07)$ \\
\hline \multicolumn{8}{|c|}{ Baseline HbA1c (\%) } \\
\hline$[11,13)$ & 3048 & $1.18 \pm 1.60$ & $2.19 \pm 1.34$ & 2535 & $2.58 \pm 1.52$ & $1.41 \pm 2.52$ & $1.93(0.49,5.41)$ \\
\hline$\geq 13$ & 1328 & $1.29 \pm 2.53$ & $2.37 \pm 1.41$ & 1101 & $2.68 \pm 2.19$ & $1.52 \pm 2.50$ & $2.04(0.37,5.72)$ \\
\hline \multicolumn{8}{|c|}{ Diabetes duration (years) } \\
\hline$<5$ & 8805 & $1.11 \pm 2.13$ & $2.18 \pm 1.29$ & 7545 & $2.35 \pm 1.84$ & $1.26 \pm 2.20$ & $1.37(0.38,3.66)$ \\
\hline$[5,10)$ & 5495 & $1.29 \pm 1.84$ & $2.33 \pm 1.46$ & 4722 & $2.64 \pm 1.79$ & $1.36 \pm 2.23$ & $1.46(0.39,3.79)$ \\
\hline$[10,15)$ & 3309 & $1.38 \pm 1.65$ & $2.41 \pm 1.37$ & 2877 & $2.83 \pm 1.68$ & $1.47 \pm 2.06$ & $1.35(0.39,3.54)$ \\
\hline$\geq 15$ & 1385 & $1.56 \pm 2.86$ & $2.54 \pm 1.40$ & 1190 & $2.99 \pm 1.85$ & $1.54 \pm 2.26$ & $1.24(0.32,3.71)$ \\
\hline Education degree & & & & & & & \\
\hline
\end{tabular}




\begin{tabular}{|c|c|c|c|c|c|c|c|}
\hline \multirow[b]{2}{*}{ Group variable } & \multicolumn{2}{|c|}{ Treatment cost at v0 } & \multirow{2}{*}{$\begin{array}{l}\text { Treatment cost at v1 } \\
\text { Mean } \pm \text { SD (\$) }\end{array}$} & \multicolumn{2}{|c|}{ Treatment cost at $v 3$} & \multirow{2}{*}{$\begin{array}{l}\text { Treatment cost } \\
\text { change (v3-v0) } \\
(\$)\end{array}$} & \multirow{2}{*}{$\begin{array}{l}\text { Times of cost increase at } 6 \\
\text { monthsł, Median (Q1, } \\
\text { Q3) }\end{array}$} \\
\hline & $\mathbf{N}$ & Mean \pm SD (\$) & & $\mathbf{N}$ & Mean \pm SD (\$) & & \\
\hline $\begin{array}{l}\text { Primary school } \\
\text { or illiterate }\end{array}$ & 5154 & $1.16 \pm 2.35$ & $2.06 \pm 1.27$ & 4334 & $2.27 \pm 1.97$ & $1.13 \pm 2.27$ & $1.54(0.33,4.52)$ \\
\hline $\begin{array}{l}\text { Junior high } \\
\text { school }\end{array}$ & 5859 & $1.23 \pm 2.03$ & $2.24 \pm 1.42$ & 5011 & $2.51 \pm 1.77$ & $1.30 \pm 2.32$ & $1.49(0.37,4.18)$ \\
\hline $\begin{array}{l}\text { Senior high } \\
\text { school }\end{array}$ & 4724 & $1.29 \pm 1.97$ & $2.45 \pm 1.43$ & 4160 & $2.74 \pm 1.77$ & $1.49 \pm 2.10$ & $1.44(0.38,3.73)$ \\
\hline Junior college & 1965 & $1.29 \pm 1.71$ & $2.46 \pm 1.32$ & 1715 & $2.83 \pm 1.64$ & $1.53 \pm 2.08$ & $1.58(0.47,4.19)$ \\
\hline $\begin{array}{l}\text { Bachelor degree } \\
\text { or higher }\end{array}$ & 1293 & $1.36 \pm 1.39$ & $2.54 \pm 1.19$ & 1115 & $2.91 \pm 1.56$ & $1.59 \pm 1.63$ & $1.53(0.47,3.48)$ \\
\hline \multicolumn{8}{|l|}{ Current residence } \\
\hline Urban & 13019 & $1.34 \pm 2.09$ & $2.44 \pm 1.39$ & 11170 & $2.75 \pm 1.88$ & $1.44 \pm 2.13$ & $1.42(0.37,3.66)$ \\
\hline Rural & 5976 & $1.02 \pm 1.92$ & $1.96 \pm 1.27$ & 5165 & $2.16 \pm 1.59$ & $1.15 \pm 2.30$ & $1.77(0.40,5.2)$ \\
\hline \multicolumn{8}{|l|}{ Patient resource } \\
\hline Outpatient clinic & 8361 & $1.32 \pm 2.15$ & $2.19 \pm 1.30$ & 7326 & $2.62 \pm 1.90$ & $1.32 \pm 2.13$ & $1.36(0.36,3.49)$ \\
\hline Inpatient ward & 10634 & $1.18 \pm 1.95$ & $2.36 \pm 1.42$ & 9009 & $2.52 \pm 1.73$ & $1.38 \pm 2.24$ & $1.68(0.39,4.69)$ \\
\hline \multicolumn{8}{|c|}{ Out of pocket costs (\%) } \\
\hline$<20$ & 2940 & $1.51 \pm 2.28$ & $2.68 \pm 1.38$ & 2513 & $2.95 \pm 1.68$ & $1.47 \pm 2.11$ & $1.07(0.30,2.95)$ \\
\hline$[20,40)$ & 7202 & $1.26 \pm 1.62$ & $2.39 \pm 1.44$ & 6253 & $2.71 \pm 1.63$ & $1.47 \pm 1.95$ & $1.55(0.44,3.94)$ \\
\hline$[40,60)$ & 4276 & $1.10 \pm 1.77$ & $2.10 \pm 1.30$ & 3682 & $2.35 \pm 1.75$ & $1.27 \pm 2.30$ & $1.75(0.41,5.11)$ \\
\hline$[60,80)$ & 2045 & $1.06 \pm 2.13$ & $1.96 \pm 1.19$ & 1737 & $2.22 \pm 1.69$ & $1.16 \pm 2.58$ & $1.73(0.32,4.82)$ \\
\hline$\geq 80$ & 2528 & $1.26 \pm 2.95$ & $2.11 \pm 1.24$ & 2150 & $2.35 \pm 2.43$ & $1.14 \pm 2.36$ & $1.42(0.34,4.04)$ \\
\hline \multicolumn{8}{|l|}{ BMI $(\mathrm{kg} / \mathrm{m} 2)$ at $\mathrm{v} 1$} \\
\hline$<24$ & 8149 & $1.25 \pm 2.10$ & $2.19 \pm 1.32$ & 6946 & $2.48 \pm 1.61$ & $1.26 \pm 2.26$ & $1.42(0.36,3.94)$ \\
\hline$[24,28)$ & 7927 & $1.24 \pm 2.15$ & $2.30 \pm 1.39$ & 6864 & $2.61 \pm 2.02$ & $1.39 \pm 2.16$ & $1.58(0.4,4.2)$ \\
\hline$\geq 28$ & 2918 & $1.23 \pm 1.54$ & $2.52 \pm 1.41$ & 2525 & $2.69 \pm 1.71$ & $1.47 \pm 2.07$ & $1.55(0.38,4.38)$ \\
\hline \multicolumn{8}{|c|}{ Macro complications } \\
\hline No & 16137 & $1.23 \pm 2.15$ & $2.28 \pm 1.36$ & 13830 & $2.56 \pm 1.86$ & $1.35 \pm 2.27$ & $1.54(0.39,4.2)$ \\
\hline Yes & 2858 & $1.30 \pm 1.33$ & $2.35 \pm 1.39$ & 2505 & $2.63 \pm 1.51$ & $1.33 \pm 1.73$ & $1.29(0.30,3.61)$ \\
\hline \multicolumn{8}{|c|}{ Micro complications } \\
\hline No & 13587 & $1.22 \pm 2.10$ & $2.25 \pm 1.37$ & 11679 & $2.53 \pm 1.89$ & $1.33 \pm 2.29$ & $1.55(0.39,4.16)$ \\
\hline Yes & 5408 & $1.29 \pm 1.90$ & $2.38 \pm 1.35$ & 4656 & $2.66 \pm 1.59$ & $1.40 \pm 1.93$ & $1.41(0.34,3.98)$ \\
\hline \multicolumn{8}{|c|}{ Number of OADs before $\mathrm{v} 1$} \\
\hline 1 & 8675 & $0.72 \pm 0.89$ & $2.20 \pm 1.24$ & 7462 & $2.44 \pm 1.59$ & $1.73 \pm 1.68$ & $3.02(1.12,7.65)$ \\
\hline 2 & 8351 & $1.47 \pm 2.46$ & $2.30 \pm 1.46$ & 7185 & $2.61 \pm 2.00$ & $1.19 \pm 2.31$ & $1.08(0.27,2.6)$ \\
\hline$\geq 3$ & 1969 & $2.61 \pm 2.78$ & $2.61 \pm 1.47$ & 1688 & $2.94 \pm 1.83$ & $0.35 \pm 3.09$ & $0.29(-0.13,0.8)$ \\
\hline \multicolumn{8}{|l|}{ BI type at $v 1$} \\
\hline Glargine & 13294 & $1.26 \pm 2.05$ & $2.47 \pm 1.29$ & 11287 & $2.72 \pm 1.87$ & $1.49 \pm 2.09$ & $1.58(0.47,4.16)$ \\
\hline Detemir & 2385 & $1.27 \pm 1.94$ & $2.76 \pm 1.32$ & 2135 & $2.94 \pm 1.82$ & $1.66 \pm 2.54$ & $1.80(0.57,4.84)$ \\
\hline $\mathrm{NPH}$ & 3316 & $1.14 \pm 2.07$ & $1.23 \pm 1.17$ & 2913 & $1.68 \pm 1.22$ & $0.56 \pm 2.14$ & $0.99(0.10,3.37)$ \\
\hline
\end{tabular}

†'Weighted means or medians were calculated for each subgroup. HbA1c, glycated hemoglobin; BMI, body mass index; OADs, oral antidiabetic drugs; BI, basal insulin; NPH, neutral protamine Hagedorn; v0, visit 0- Before initiation of BI; v1, visit 1- Immediately after the initiation of BI; v3, visit 3- End of the study at month 6; SD, standard deviation; Q1, 25th percentile; Q3, 75th percentile.

${ }^{\ddagger}$ Times of cost increase $=($ Absolute cost increase $) /$ Self-report cost at v0.

\subsection{Cost Proportion}

The number of OADs used at visit 0 decreased substantially at visit 1 and remained stable at the following visits. BI dose and total insulin dose decreased at visit 3 , while the frequency of SMBG and minor hypoglycemia increased at visits 2 and 3 (Table 3). The cost of Insulin accounted for the highest proportion (approximately $50 \%$ ) of costs, with costs of OAD medications ranking second (37.3\%) (Table 4).

Table 3. Changes in factors related to cost of treatment".

\begin{tabular}{|c|c|c|c|c|}
\hline \multirow[t]{2}{*}{ Variables } & $\begin{array}{l}\text { Before initiation of BI: } v 0 \\
(n=18995)\end{array}$ & $\begin{array}{l}\text { Immediately after the } \\
\text { initiation of BI: v1 }(n=18995)\end{array}$ & $\begin{array}{l}\text { Mid-term at month } \\
\text { 3: v2 }(n=17253)\end{array}$ & $\begin{array}{l}\text { End of the study at } \\
\text { month 6: v3 }(n=16336)\end{array}$ \\
\hline & Mean \pm SD & Mean \pm SD & Mean \pm SD & Mean \pm SD \\
\hline OAD number & $1.67 \pm 0.25$ & $1.24 \pm 0.32$ & $1.31 \pm 0.31$ & $1.31 \pm 0.31$ \\
\hline BI dose (IU/day) & - & $11.50 \pm 1.68$ & $10.91 \pm 2.58$ & $10.53 \pm 2.90$ \\
\hline Insulin dose (IU/day) & - & $17.67 \pm 4.63$ & $16.57 \pm 4.98$ & $15.94 \pm 5.06$ \\
\hline SMBG frequency per month & $5.07 \pm 3.73$ & - & $6.94 \pm 3.58$ & $6.09 \pm 2.85$ \\
\hline Needle number per week & - & - & $3.04 \pm 3.50$ & $2.73 \pm 3.21$ \\
\hline Hypoglycemia frequency per month & $0.15 \pm 0.33$ & - & $0.22 \pm 0.30$ & $0.20 \pm 0.42$ \\
\hline
\end{tabular}

'Weighted means were calculated for each variable according to their values in each region and the weights for each region. BI, basal insulin; OADs, oral antidiabetic drugs; SMBG, self-monitoring of blood glucose; v0, visit 0; v1, visit 1; v2, visit 2; v3, visit 3; SD, standard deviation. 
Table 4. Cost (\$) of each item and cost proportion (\%) at each visit".

\begin{tabular}{|c|c|c|c|c|c|c|c|c|}
\hline \multirow{2}{*}{ Variable } & \multicolumn{2}{|c|}{$\begin{array}{l}\text { Before initiation of } \mathrm{BI} \text { : v0 } \\
(\mathrm{N}=\mathbf{1 8 9 9 5 )}\end{array}$} & \multicolumn{2}{|c|}{$\begin{array}{l}\text { Immediately after the } \\
\text { initiation of BI: v1 ( }=18995)\end{array}$} & \multicolumn{2}{|c|}{$\begin{array}{l}\text { Mid-term at month 3: v2 } \\
(\mathrm{N}=17253)\end{array}$} & \multicolumn{2}{|c|}{$\begin{array}{l}\text { End of the study at month } 6: \\
v 3(N=16335)\end{array}$} \\
\hline & Mean \pm SD & $\begin{array}{l}\text { Proportio } \\
\text { n }(\%)\end{array}$ & Mean \pm SD & $\begin{array}{l}\text { Proportion } \\
\text { (\%) }\end{array}$ & Mean \pm SD & $\begin{array}{l}\text { Proportio } \\
\text { n (\%) }\end{array}$ & Mean \pm SD & $\begin{array}{l}\text { Proportion } \\
\text { (\%) }\end{array}$ \\
\hline OAD cost $(\$)$ & $1.10 \pm 0.73$ & 88.6 & $0.93 \pm 0.43$ & 40.9 & $0.97 \pm 0.52$ & 36.4 & $0.96 \pm 0.54$ & 37.3 \\
\hline Insulin cost (\$) & - & - & $1.35 \pm 0.30$ & 59.1 & $1.28 \pm 0.34$ & 47.8 & $1.23 \pm 0.36$ & 47.9 \\
\hline Needle cost (\$) & - & - & - & - & $0.23 \pm 0.14$ & 8.5 & $0.21 \pm 0.12$ & 8.1 \\
\hline SMBG cost (\$) & $0.14 \pm 0.11$ & 11.2 & - & - & $0.19 \pm 0.10$ & 7.1 & $0.17 \pm 0.09$ & 6.6 \\
\hline Hypoglycemia cost (\$) & $0.00 \pm 0.00$ & 0.2 & - & - & $0.00 \pm 0.00$ & 0.1 & $0.00 \pm 0.01$ & 0.1 \\
\hline Total cost $(\$)$ & $1.25 \pm 0.74$ & 100.0 & $2.29 \pm 0.51$ & 100.0 & $2.68 \pm 0.66$ & 100.0 & $2.57 \pm 0.68$ & 100.0 \\
\hline
\end{tabular}

${ }^{\dagger}$ Weighted means of cost for each variable were calculated. OADs, oral antidiabetic drugs; SMBG, self-monitoring of blood glucose; v0, visit 0; v1, visit 1; v2, visit 2; v3, visit 3; SD, standard deviation.

\section{Discussion}

This large registry study showed that the introduction of BI therapy may increase the daily treatment cost (including OADs, insulin, SMBG, and dealing with hypoglycemia) by 1.5 times at 6 months, with a $2.2 \%$ reduction in HbAlc levels and a slight increase in frequency of hypoglycemia. Higher HbAlc level and longer diabetes duration at baseline were related to the higher treatment cost increase after initiation of BI.

Daily treatment cost and change of daily treatment cost at month-6 increased with the growing of baseline $\mathrm{HbAlc}$ level and prolonged diabetes duration. Also, the ones with longer diabetes duration ( $\geq 15$ years) had lower HbAlc reduction at month $6(1.75 \%$ vs. $2.47 \%)$, compared to the ones with shorter diabetes duration $(<5$ years). This is consistent with a sub-analysis from the MOTIV study which found that patients with shorter duration of diabetes needed lower dose of insulin (which means lower cost of insulin) compared with those having longer duration of diabetes to achieve the same reduction in their HbA1c levels [34]. Furthermore, the ones with higher baseline $\mathrm{HbA} 1 \mathrm{c}$ level or longer diabetes duration had higher frequency of minor hypoglycemia (Table 7). All of these suggest that to the insulin-naïve patients with T2DM uncontrolled by OADs, early initiation of BI therapy might provide an opportunity to achieve treatment goals with low cost and low risk of hypoglycemia.

After adding BI to an OAD-only treatment, cost of insulin therapy accounted for $48 \%$ of the total treatment costs. This percentage was similar to that observed in Canada (48.6\%) [35], but is lower than that in the United States (75.5\%) [36]. OADs medication costs accounted for $36.0 \%$ of the total treatment cost, higher than that among insulin users in western countries (range: $19.5 \%-27.0 \%$ ) $[35,36]$. This is not a surprising finding when considering the differences between Asian and Western cultures. Chinese patients prefer to use OADs rather than insulin injection, because they believe being treated with insulin causes family and friends to be more concerned about them, and that they will also be more dependent on their doctors [37]. Most Chinese patients view the insulin treatment as the last choice.

For patients using insulin injections, SMBG is recognized as a core component of effective diabetes self-management. However, little is known about the real-world frequency and true costs associated with SMBG. This study showed that following addition of BI for 3 and 6 months, the frequency of SMBG doubled (from 2 times/month to 4 times/month) and SMBG-related costs accounted for around $7 \%$ of the total treatment cost for insulin users; the average cost of SMBG (including blood testing strips and lancets) per patient per day was around $\$ 0.20$. The percentage and daily cost of SMBG in ORBIT were much lower than those observed in western countries $[35,36]$ wherein SMBG accounted for approximately $23.1 \%$ to $41.6 \%$ of the total diabetes-related pharmacy costs, and the average cost per testing strip was $\$ 0.79$ to $\$ 0.98$. The difference between China and western countries might be due to the different methods of data collection. Previous studies on SMBG in western countries were all retrospective studies, with the number of blood testing strips calculated according to pharmacy-based SMBG testing. Moreover, in the aforementioned studies, at least one pharmacy claim for blood glucose testing strips was required. However, in ORBIT study, SMBG behavior was home-based instead of as prescribed by a physician, and patients decided whether to perform SMBG or not. Hence, not all patients in the ORBIT study had SMBG. Compared with previous studies that calculated SMBG cost according to pharmacy claim records (record of blood testing strips), the results of ORBIT may better reflect home-based SMBG frequency and cost, which is more pertinent to the practical self-management behavior of patients in China. Owing to the lack of awareness and skill of performing SMBG, home-based SMBG costs accounted for a lower percentage of costs in diabetes treatment.

This study also collected data on the frequency of hypoglycemia. Most hypoglycemic events were minor, and no requirement for medication or formal health care. Patients always dealt with hypoglycemia by food intake or more rest. Thus, costs of dealing with hypoglycemia were relatively low, accounting for only $0.1 \%$ of the total costs.

Strengths of this study included the large sample size (almost 20,000 participants) drawn from all major regions of China among a clinically relevant heterogeneous population. This enables economically valid assessment of the influences of introducing BI therapy on cost changes at the regional and hospital level under real-life clinical practice conditions. However, as shown in Table 1 and 2, differences exist in daily treatment cost change and times of cost increase among regions and hospitals, and attention needs to be paid when applying the 
results of this study to specific regions or hospitals.

In ORBIT, the three most commonly used BIs (insulin glargine, insulin detemir, and NPH insulin) were considered as a whole group to assess the overall daily costs following addition of these BIs to insulin-naïve T2DM patients. Results on the costs of BI types in the subgroups were crude results without adjusting for the confounding factors. Therefore, further research have been planned to focus on cost comparison among the three most commonly used BIs in the real world, with adjustment for covariate variables such as baseline variables.

\section{Conclusions}

Adding-on BI therapy may increase the daily treatment cost by 1.5 times at 6 months. Early initiation of BI therapy may provide an opportunity to achieve treatment goals with low cost and low risk of hypoglycemia. For patients who are insulin naïve and uncontrolled by oral antidiabetic drugs, physicians and patients can predict the cost change once initiated basal insulin and make decision accordingly. Further studies are needed to compare the cost changes caused by specific basal insulin initiation, such as insulin glargine, insulin detemir, and NPH insulin.

\section{Author Contributions}

conceptualization, D. Z. and P. Z.; methodology, D. Z.; formal analysis, X. L. and J. J.; investigation, J. L. and W. J.; data curation, D. Z.; writing - original draft preparation, D. Z.; writing — review and editing, P. Z.; supervision, L. J.; funding acquisition, L. J.

\section{Funding}

This study was funded by Sanofi-Aventis (Shanghai, China).

\section{Conflicts of Interest}

Linong Ji reports receiving consulting and lecture fees from Eli Lilly, Bristol-Myers Squibb, Novartis, Novo Nordisk, Merck, Bayer, Takeda, Sanofi, Roche, and Boehringer Ingelheim, and research grants from Roche and Sanofi. All other authors declare no conflict of interest.

\section{List of Supporting Information}

Table 5. Calculation of the weights for each region.

\begin{tabular}{|c|c|c|c|c|}
\hline $\begin{array}{l}\text { Regions and } \\
\text { provinces }\end{array}$ & $\begin{array}{l}\text { Population in each } \\
\text { province (Unit: 10000) }\end{array}$ & $\begin{array}{l}\text { Prevalence of type } 2 \text { diabetes in } \\
\text { each province }(\%)\end{array}$ & $\begin{array}{l}\text { Number of patients with type } 2 \text { diabetes } \\
\text { in each province }\end{array}$ & $\begin{array}{l}\text { Weight for each } \\
\text { region }^{\dagger}\end{array}$ \\
\hline \multicolumn{5}{|l|}{ Southwest } \\
\hline Yunnan & 4333 & 7.3 & 3163090 & \\
\hline Guizhou & 3837 & 7.3 & 2801010 & \\
\hline Sichuan & 8673 & 1.4 & 1214220 & \\
\hline Chongqing & 3107 & 12.4 & 3852680 & \\
\hline Guangxi & 4822 & 10.4 & 5014880 & \\
\hline All & & & 16045880 & 0.10 \\
\hline \multicolumn{5}{|l|}{ Northwest } \\
\hline Gansu & 2593 & 10.4 & 2696720 & \\
\hline Qinghai & 529 & 7.3 & 386170 & \\
\hline Ningxia & 572 & 7.3 & 417560 & \\
\hline Tibet & 267 & 7.3 & 194910 & \\
\hline Xinjiang & 1905 & 14.3 & 2724150 & \\
\hline All & & & 6419510 & 0.04 \\
\hline \multicolumn{5}{|c|}{ Mid-Yangtze River } \\
\hline Hubei & 5988 & 10.4 & 6227520 & \\
\hline Hunan & 6629 & 7.3 & 4839170 & \\
\hline Jiangxi & 4222 & 10.4 & 4390880 & \\
\hline Anhui & 6338 & 14.3 & 9063340 & \\
\hline All & & & 24520910 & 0.16 \\
\hline \multicolumn{5}{|c|}{ Mid-Yellow River } \\
\hline Shaanxi & 3674 & 7.3 & 2682020 & \\
\hline Shanxi & 3294 & 12.4 & 4084560 & \\
\hline Henan & 9613 & 14.3 & 13746590 & \\
\hline Inner Mongolia & 2379 & 14.3 & 3401970 & \\
\hline All & & & 23915140 & 0.15 \\
\hline \multicolumn{5}{|l|}{ South Coast } \\
\hline Fujian & 3466 & 12.4 & 4297840 & \\
\hline Guangdong & 7859 & 18.75 & 14735625 & \\
\hline Hainan & 803 & 10.4 & 835120 & \\
\hline All & & & 19868585 & 0.13 \\
\hline \multicolumn{5}{|l|}{ East Coast } \\
\hline Shanghai & 1625 & 18.75 & 3046875 & \\
\hline Jiangsu & 7381 & 12.4 & 9152440 & \\
\hline
\end{tabular}




\begin{tabular}{lllll}
\hline $\begin{array}{l}\text { Regions and } \\
\text { provinces }\end{array}$ & $\begin{array}{l}\text { Population in each } \\
\text { province (Unit: 10000) }\end{array}$ & $\begin{array}{l}\text { Prevalence of type 2 diabetes in } \\
\text { each province (\%) }\end{array}$ & $\begin{array}{l}\text { Number of patients with type 2 diabetes } \\
\text { in each province }\end{array}$ & $\begin{array}{l}\text { Weight for each } \\
\text { region }^{\dagger}\end{array}$ \\
\hline Zhejiang & 4647 & 12.4 & 5762280 \\
All & & & 17961595 & 0.12 \\
North Coast & & 18.75 & 2668125 \\
Beijing & 1423 & 18.75 & 1888125 \\
Tianjin & 1007 & 18.75 & 12628125 \\
Hebei & 6735 & 14.3 & 12987260 & \\
Shandong & 9082 & & 30171635 \\
All & & 14.3 & & 0.20 \\
Northeast & & 18.75 & 6010290 & \\
Liaoning & 4203 & 12.4 & 4060625 \\
Jilin & 2699 & & 4728120 \\
Heilongjiang & 3813 & & 15799035 \\
All & & & 154702290 \\
Total & & & 0.10 \\
\hline
\end{tabular}

'Weight for each region was calculated by using their number of patients with type 2 diabetes divided by the total number of patients, e.g., the weight for Southwest equal to $16045880 / 154702290=0.10$

Table 6. Percentage of patients in different subgroups in overall and eight geographical regions, $n$ (\%).

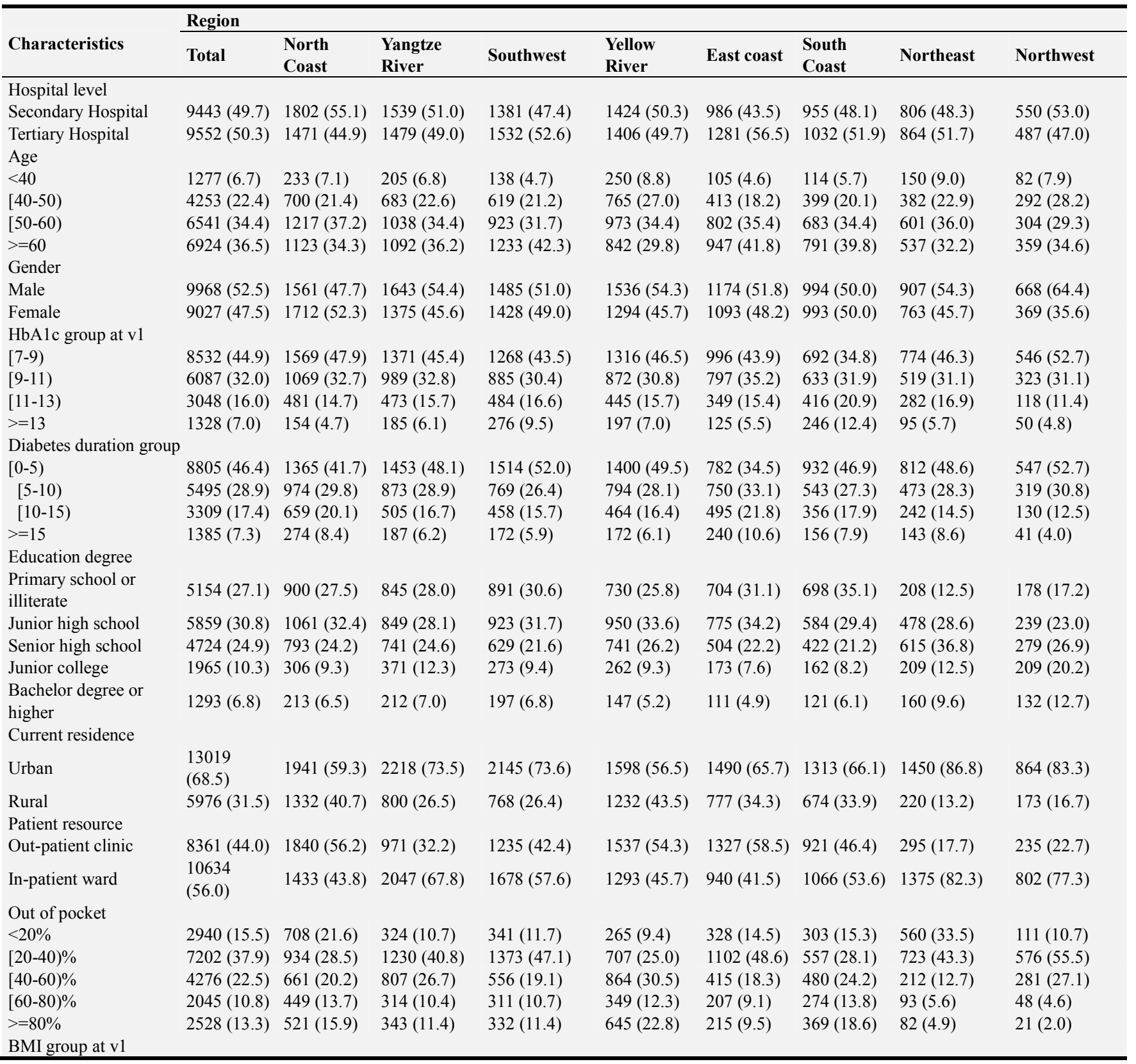




\begin{tabular}{|c|c|c|c|c|c|c|c|c|c|}
\hline \multirow[b]{2}{*}{ Characteristics } & \multicolumn{9}{|l|}{ Region } \\
\hline & Total & $\begin{array}{l}\text { North } \\
\text { Coast }\end{array}$ & $\begin{array}{l}\text { Yangtze } \\
\text { River }\end{array}$ & Southwest & $\begin{array}{l}\text { Yellow } \\
\text { River }\end{array}$ & East coast & $\begin{array}{l}\text { South } \\
\text { Coast }\end{array}$ & Northeast & Northwest \\
\hline$<24$ & 8149 (42.9) & $1105(33.8)$ & $1466(48.6)$ & $1352(46.4)$ & $1099(38.8)$ & $1074(47.4)$ & $1137(57.3)$ & $493(29.5)$ & $423(40.8)$ \\
\hline$[24-28)$ & $7927(41.7)$ & $1493(45.6)$ & $1171(38.8)$ & $1154(39.6)$ & $1302(46.0)$ & $896(39.5)$ & $662(33.3)$ & $788(47.2)$ & $461(44.5)$ \\
\hline$>=28$ & $2918(15.4)$ & 675 (20.6) & $381(12.6)$ & $407(14.0)$ & $429(15.2)$ & $297(13.1)$ & $187(9.4)$ & $389(23.3)$ & $153(14.8)$ \\
\hline \multicolumn{10}{|c|}{ Regular OAD treatment duration group } \\
\hline$[0-3)$ & $6998(36.9)$ & $1147(35.1)$ & $1131(37.5)$ & $1179(40.5)$ & $1104(39.0)$ & $521(23.0)$ & $730(36.8)$ & $722(43.2)$ & $464(44.7)$ \\
\hline$[3-6)$ & $4373(23.0)$ & $733(22.4)$ & $674(22.3)$ & $710(24.4)$ & $657(23.2)$ & $538(23.7)$ & $431(21.7)$ & $372(22.3)$ & $258(24.9)$ \\
\hline$[6-9)$ & $2974(15.7)$ & $520(15.9)$ & $506(16.8)$ & $410(14.1)$ & $429(15.2)$ & $423(18.7)$ & $303(15.3)$ & $232(13.9)$ & $151(14.6)$ \\
\hline$>=9$ & $4645(24.5)$ & $871(26.6)$ & $706(23.4)$ & $614(21.1)$ & $640(22.6)$ & $785(34.6)$ & $521(26.2)$ & $344(20.6)$ & $164(15.8)$ \\
\hline \multicolumn{10}{|c|}{ Macro complication } \\
\hline No & $\begin{array}{l}16137 \\
(85.0)\end{array}$ & $2630(80.4)$ & $2581(85.5)$ & $2572(88.3)$ & $2305(81.4)$ & $2023(89.2)$ & $1793(90.2)$ & $1307(78.3)$ & $926(89.3)$ \\
\hline \multicolumn{9}{|c|}{ Micro complication } & $111(10.7)$ \\
\hline No & $\begin{array}{l}13587 \\
(71.5)\end{array}$ & $2260(69.0)$ & $2250(74.6)$ & $2120(72.8)$ & $2024(71.5)$ & $1926(85.0)$ & $1468(73.9)$ & $858(51.4)$ & $681(65.7)$ \\
\hline Yes & $5408(28.5)$ & $1013(31.0)$ & $768(25.4)$ & $793(27.2)$ & $806(28.5)$ & $341(15.0)$ & $519(26.1)$ & $812(48.6)$ & $356(34.3)$ \\
\hline \multicolumn{10}{|c|}{ Number of OAD at v0 } \\
\hline 1 & $8675(45.7)$ & $1260(38.5)$ & $1317(43.6)$ & $1297(44.5)$ & $1339(47.3)$ & $840(37.1)$ & $700(35.2)$ & $1315(78.7)$ & $607(58.5)$ \\
\hline 2 & $8351(44.0)$ & $1638(50.0)$ & $1413(46.8)$ & $1273(43.7)$ & $1268(44.8)$ & $1113(49.1)$ & $929(46.8)$ & $336(20.1)$ & $381(36.7)$ \\
\hline$>=3$ & $1969(10.4)$ & $375(11.5)$ & $288(9.5)$ & $343(11.8)$ & $223(7.9)$ & $314(13.9)$ & $358(18.0)$ & $19(1.1)$ & $49(4.7)$ \\
\hline \multicolumn{10}{|l|}{ BI type at v1 } \\
\hline Glargine & $\begin{array}{l}13294 \\
(70.0)\end{array}$ & $2138(65.3)$ & $2357(78.1)$ & $1923(66.0)$ & $1515(53.5)$ & $1768(78.0)$ & $1516(76.3)$ & 1267 (75.9) & $810(78.1)$ \\
\hline Detemir & 2385 (12.6) & $349(10.7)$ & $285(9.4)$ & $411(14.1)$ & $314(11.1)$ & $210(9.3)$ & $340(17.1)$ & $320(19.2)$ & $156(15.0)$ \\
\hline $\mathrm{NPH}$ & $3316(17.5)$ & $786(24.0)$ & $376(12.5)$ & 579 (19.9) & $1001(35.4)$ & $289(12.7)$ & $131(6.6)$ & $83(5.0)$ & $71(6.8)$ \\
\hline
\end{tabular}

HbA1c, glycated hemoglobin; BMI, body mass index; OADs, oral antidiabetic drugs; BI, basal insulin; NPH, neutral protamine Hagedorn; v0, visit 0; v1, visit 1.

Table 7. Clinical outcome at month 6 in overall and different subgroups.

\begin{tabular}{|c|c|c|c|c|}
\hline \multirow{2}{*}{ Group variable } & \multirow{2}{*}{$\mathbf{N}$} & \multirow{2}{*}{$\begin{array}{l}\text { HbA1c reduction (\%) } \\
\text { Mean } \pm \text { SD }\end{array}$} & \multirow{2}{*}{$\begin{array}{l}\text { Minor hypoglycemia increase (times/person/year) } \\
\text { Mean } \pm \text { SD }\end{array}$} & \multirow{2}{*}{$\begin{array}{l}\text { Weight gain }(\mathrm{kg}) \\
\text { Mean } \pm \text { SD }\end{array}$} \\
\hline & & & & \\
\hline Total & 18,995 & $2.15 \pm 2.07$ & $0.68 \pm 15.60$ & $0.10 \pm 2.94$ \\
\hline \multicolumn{5}{|l|}{ Regions } \\
\hline North coast & 3,273 & $1.98 \pm 1.86$ & $0.78 \pm 14.86$ & $0.05 \pm 2.87$ \\
\hline Yangtze River & 3,018 & $2.49 \pm 2.15$ & $1.03 \pm 25.39$ & $-0.13 \pm 2.66$ \\
\hline Southwest & 2,913 & $2.15 \pm 2.19$ & $1.88 \pm 14.55$ & $0.45 \pm 3.15$ \\
\hline Yellow River & 2,830 & $2.24 \pm 2.07$ & $0.27 \pm 14.39$ & $0.02 \pm 3.02$ \\
\hline East coast & 2,267 & $1.77 \pm 1.84$ & $0.24 \pm 8.22$ & $0.42 \pm 2.79$ \\
\hline South coast & 1,987 & $2.47 \pm 2.31$ & $0.92 \pm 14.53$ & $0.41 \pm 2.80$ \\
\hline Northeast & 1,670 & $2.05 \pm 2.04$ & $-0.28 \pm 7.87$ & $-0.50 \pm 3.12$ \\
\hline Northwest & 1,037 & $1.87 \pm 1.91$ & $-0.20 \pm 8.84$ & $0.08 \pm 3.22$ \\
\hline \multicolumn{5}{|l|}{ Hospital level } \\
\hline Secondary & 9443 & $2.25 \pm 2.13$ & $0.21 \pm 12.21$ & $0.23 \pm 2.87$ \\
\hline Tertiary & 9552 & $2.04 \pm 1.99$ & $1.18 \pm 18.53$ & $-0.03 \pm 3.01$ \\
\hline \multicolumn{5}{|l|}{ Age (years) } \\
\hline$<40$ & 1277 & $2.68 \pm 2.31$ & $1.04 \pm 11.86$ & $-0.38 \pm 3.45$ \\
\hline$[40,50)$ & 4253 & $2.21 \pm 2.04$ & $0.89 \pm 11.00$ & $0.04 \pm 3.14$ \\
\hline$[50,60)$ & 6541 & $2.15 \pm 2.06$ & $0.78 \pm 20.34$ & $0.21 \pm 2.81$ \\
\hline$\geq 60$ & 6924 & $2.01 \pm 2.03$ & $0.39 \pm 13.20$ & $0.13 \pm 2.83$ \\
\hline \multicolumn{5}{|l|}{ Gender } \\
\hline Male & 9968 & $2.20 \pm 2.09$ & $0.94 \pm 16.66$ & $-0.00 \pm 3.14$ \\
\hline Female & 9027 & $2.09 \pm 2.04$ & $0.39 \pm 14.31$ & $0.23 \pm 2.71$ \\
\hline \multicolumn{5}{|l|}{ Baseline HbA1c (\%) } \\
\hline$[7,8)$ & 8532 & $0.91 \pm 1.14$ & $0.14 \pm 18.82$ & $-0.14 \pm 2.80$ \\
\hline$[9,11)$ & 6087 & $2.28 \pm 1.42$ & $0.89 \pm 12.53$ & $0.07 \pm 2.97$ \\
\hline$[11,13)$ & 3048 & $3.83 \pm 1.74$ & $1.47 \pm 12.01$ & $0.53 \pm 3.08$ \\
\hline$\geq 13$ & 1328 & $6.13 \pm 2.25$ & $1.58 \pm 10.95$ & $0.91 \pm 3.17$ \\
\hline \multicolumn{5}{|c|}{ Diabetes duration (years) } \\
\hline$<5$ & 8805 & $2.47 \pm 2.19$ & $0.75 \pm 17.13$ & $-0.03 \pm 3.07$ \\
\hline$[5,10)$ & 5495 & $1.88 \pm 1.89$ & $0.43 \pm 13.52$ & $0.15 \pm 2.87$ \\
\hline$[10,15)$ & 3309 & $1.91 \pm 1.91$ & $0.68 \pm 14.72$ & $0.30 \pm 2.77$ \\
\hline$\geq 15$ & 1385 & $1.75 \pm 1.97$ & $1.14 \pm 14.96$ & $0.31 \pm 2.72$ \\
\hline \multicolumn{5}{|l|}{ Education degree } \\
\hline $\begin{array}{l}\text { Primary school or } \\
\text { illiterate }\end{array}$ & 5154 & $2.31 \pm 2.18$ & $0.61 \pm 14.75$ & $0.35 \pm 2.87$ \\
\hline
\end{tabular}




\begin{tabular}{|c|c|c|c|c|}
\hline \multirow{2}{*}{ Group variable } & \multirow{2}{*}{$\mathbf{N}$} & \multirow{2}{*}{$\begin{array}{l}\text { HbA1c reduction }(\%) \\
\text { Mean } \pm \text { SD }\end{array}$} & \multirow{2}{*}{$\begin{array}{l}\text { Minor hypoglycemia increase (times/person/year) } \\
\text { Mean } \pm \text { SD }\end{array}$} & \multirow{2}{*}{$\begin{array}{l}\text { Weight gain (kg) } \\
\text { Mean } \pm \text { SD }\end{array}$} \\
\hline & & & & \\
\hline Junior high school & 5859 & $2.18 \pm 2.11$ & $0.91 \pm 20.05$ & $0.25 \pm 3.02$ \\
\hline Senior high school & 4724 & $2.02 \pm 1.95$ & $0.53 \pm 13.63$ & $-0.08 \pm 2.86$ \\
\hline Junior college & 1965 & $2.03 \pm 1.95$ & $0.79 \pm 9.62$ & $-0.24 \pm 3.04$ \\
\hline $\begin{array}{l}\text { Bachelor degree or } \\
\text { higher }\end{array}$ & 1293 & $2.04 \pm 2.00$ & $0.31 \pm 8.78$ & $-0.31 \pm 2.88$ \\
\hline \multicolumn{5}{|l|}{ Current residence } \\
\hline Rural & 5976 & $2.42 \pm 2.19$ & $0.71 \pm 21.09$ & $0.38 \pm 2.96$ \\
\hline \multicolumn{5}{|l|}{ Patient resource } \\
\hline Outpatient clinic & 8361 & $1.88 \pm 1.85$ & $0.65 \pm 18.90$ & $0.20 \pm 2.72$ \\
\hline Inpatient ward & 10634 & $2.37 \pm 2.20$ & $0.70 \pm 12.28$ & $0.03 \pm 3.11$ \\
\hline \multicolumn{5}{|c|}{ Out of pocket costs $(\%)$} \\
\hline$<20$ & 2940 & $1.96 \pm 2.00$ & $0.46 \pm 9.59$ & $0.12 \pm 2.89$ \\
\hline$[20,40)$ & 7202 & $2.04 \pm 1.97$ & $1.02 \pm 18.06$ & $-0.05 \pm 2.96$ \\
\hline$[60,80)$ & 2045 & $2.44 \pm 2.19$ & $-0.14 \pm 16.12$ & $0.17 \pm 3.05$ \\
\hline$\geq 80$ & 2528 & $2.12 \pm 1.95$ & $0.37 \pm 17.12$ & $0.34 \pm 2.70$ \\
\hline \multicolumn{5}{|l|}{ BMI $(\mathrm{kg} / \mathrm{m} 2)$ at $\mathrm{v} 1$} \\
\hline$<24$ & 8149 & $2.38 \pm 2.21$ & $0.72 \pm 12.83$ & $0.93 \pm 2.67$ \\
\hline$[24,28)$ & 7927 & $2.00 \pm 1.97$ & $0.72 \pm 19.16$ & $-0.21 \pm 2.79$ \\
\hline$\geq 28$ & 2918 & $1.90 \pm 1.84$ & $0.47 \pm 11.09$ & $-1.33 \pm 3.32$ \\
\hline \multicolumn{5}{|c|}{ Regular OAD treatment duration (years) } \\
\hline$<3$ & 6998 & $2.60 \pm 2.21$ & $1.00 \pm 17.97$ & $-0.05 \pm 3.11$ \\
\hline$[3,6)$ & 4373 & $1.94 \pm 1.99$ & $0.30 \pm 13.00$ & $0.13 \pm 2.92$ \\
\hline$[6,9)$ & 2974 & $1.87 \pm 1.88$ & $0.12 \pm 16.57$ & $0.18 \pm 2.82$ \\
\hline$\geq 9$ & 4645 & $1.84 \pm 1.90$ & $0.90 \pm 13.14$ & $0.26 \pm 2.76$ \\
\hline \multicolumn{5}{|l|}{ Macro complications } \\
\hline No & 16137 & $2.19 \pm 2.08$ & $0.85 \pm 15.54$ & $0.12 \pm 2.95$ \\
\hline Yes & 2858 & $1.92 \pm 1.98$ & $-0.25 \pm 15.88$ & $0.04 \pm 2.89$ \\
\hline \multicolumn{5}{|l|}{ Micro complications } \\
\hline No & 13587 & $2.19 \pm 2.06$ & $0.86 \pm 15.83$ & $0.12 \pm 2.93$ \\
\hline 1 & 8675 & $2.40 \pm 2.16$ & $0.73 \pm 12.59$ & $-0.00 \pm 2.97$ \\
\hline 2 & 8351 & $1.98 \pm 1.96$ & $0.57 \pm 12.49$ & $0.14 \pm 2.88$ \\
\hline$\geq 3$ & 1969 & $1.75 \pm 1.95$ & $0.90 \pm 31.48$ & $0.43 \pm 3.06$ \\
\hline \multicolumn{5}{|l|}{ BI type at v1 } \\
\hline Glargine & 13294 & $2.09 \pm 2.01$ & $0.27 \pm 11.53$ & $0.06 \pm 2.89$ \\
\hline Detemir & 2385 & $2.17 \pm 2.01$ & $1.77 \pm 26.04$ & $-0.20 \pm 2.88$ \\
\hline NPH & 3316 & $2.35 \pm 2.29$ & $1.45 \pm 18.72$ & $0.49 \pm 3.13$ \\
\hline
\end{tabular}

HbA1c, glycated hemoglobin; BMI, body mass index; OADs, oral antidiabetic drugs; BI, basal insulin; NPH, neutral protamine Hagedorn; v0, visit 0; v1, visit 1; v3, visit 3; SD, standard deviation.

\section{Acknowledgements}

The authors would like to thank the many investigators and patients for their participation, without which this study would not have been possible.

\section{References}

[1] Guariguata L, Whiting DR, Hambleton I, et al. Global estimates of diabetes prevalence for 2013 and projections for 2035. Diabetes Res Clin Pract 2014; 103: 137-149.

[2] Li H, Oldenburg B, Chamberlain C, et al. Diabetes prevalence and determinants in adults in China mainland from 2000 to 2010: a systematic review. Diabetes Res Clin Pract 2012; 98: 226-235.

[3] Yang SH, Dou KF, Song WJ. Prevalence of diabetes among men and women in China. N Engl J Med 2010; 362: 2425-2426; author reply 2426.
[4] Xu Y, Wang L, He J, et al. Prevalence and control of diabetes in Chinese adults. JAMA 2013; 310: 948-959.

[5] Alberti KG, Zimmet PZ. Definition, diagnosis and classification of diabetes mellitus and its complications. Part 1: diagnosis and classification of diabetes mellitus provisional report of a WHO consultation. Diabet Med 1998; 15: 539-553.

[6] Hanefeld M. Use of insulin in type 2 diabetes: what we learned from recent clinical trials on the benefits of early insulin initiation. Diabetes Metab 2014; 40: 391-399.

[7] Turner RC, Cull CA, Frighi V, et al. Glycemic control with diet, sulfonylurea, metformin, or insulin in patients with type 2 diabetes mellitus: progressive requirement for multiple therapies (UKPDS 49). UK Prospective Diabetes Study (UKPDS) Group. JAMA 1999; 281: 2005-2012.

[8] Garber AJ. Treat-to-target trials: uses, interpretation and review of concepts. Diabetes Obes Metab 2014; 16: 193-205.

[9] Holman RR, Farmer AJ, Davies MJ, et al. Three-year efficacy of complex insulin regimens in type 2 diabetes. N Engl J Med 2009; 361: 1736-1747. 
[10] Khunti K, Caputo S, Damci T, et al. The safety and efficacy of adding once-daily insulin detemir to oral hypoglycaemic agents in patients with type 2 diabetes in a clinical practice setting in 10 countries. Diabetes Obes Metab 2012; 14: 1129-1136.

[11] Seaquist ER, Anderson J, Childs B, et al. Hypoglycemia and diabetes: a report of a workgroup of the American Diabetes Association and the Endocrine Society. Diabetes Care 2013; 36: 1384-1395.

[12] Tsai ST, Pathan F, Ji L, et al. First insulinization with basal insulin in patients with Type 2 diabetes in a real-world setting in Asia. J Diabetes 2011; 3: 208-216.

[13] Hermansen K, Davies M, Derezinski T, et al. A 26-week, randomized, parallel, treat-to-target trial comparing insulin detemir with NPH insulin as add-on therapy to oral glucose-lowering drugs in insulin-naive people with type 2 diabetes. Diabetes Care 2006; 29: 1269-1274.

[14] Philis-Tsimikas A, Charpentier G, Clauson P, et al. Comparison of once-daily insulin detemir with NPH insulin added to a regimen of oral antidiabetic drugs in poorly controlled type 2 diabetes. Clin Ther 2006; 28: 1569-1581.

[15] Riddle MC, Rosenstock J, Gerich J, et al. The treat-to-target trial: randomized addition of glargine or human NPH insulin to oral therapy of type 2 diabetic patients. Diabetes Care 2003; 26: 3080-3086.

[16] Rosenstock J, Davies M, Home PD, et al. A randomised, 52-week, treat-to-target trial comparing insulin detemir with insulin glargine when administered as add-on to glucose-lowering drugs in insulin-naive people with type 2 diabetes. Diabetologia 2008; 51: 408-416.

[17] Yki-Järvinen H, Kauppinen-Mäkelin R, Tiikkainen M, et al. Insulin glargine or NPH combined with metformin in type 2 diabetes: the LANMET study. Diabetologia 2006; 49: 442-451.

[18] Dornhorst A, Lüddeke HJ, Sreenan S, et al. Insulin detemir improves glycaemic control without weight gain in insulin-naive patients with type 2 diabetes: subgroup analysis from the PREDICTIVE study. Int J Clin Pract 2008; 62: 659-665.

[19] Hajos TR, Pouwer F, de Grooth R, et al. Initiation of insulin glargine in patients with Type 2 diabetes in suboptimal glycaemic control positively impacts health-related quality of life. A prospective cohort study in primary care. Diabet Med 2011; 28: 1096-1102.

[20] Home P, Naggar NE, Khamseh M, et al. An observational non-interventional study of people with diabetes beginning or changed to insulin analogue therapy in non-Western countries: the A1chieve study. Diabetes Res Clin Pract 2011; 94: 352-363.

[21] Marre M, Pinget M, Gin H, et al. Insulin detemir improves glycaemic control with less hypoglycaemia and no weight gain: 52-week data from the PREDICTIVE study in a cohort of French patients with type 1 or type 2 diabetes. Diabetes Metab 2009; 35: 469-475.

[22] Schreiber SA, Ferlinz K, Haak T. The long-term efficacy of insulin glargine plus oral antidiabetic agents in a 32-month observational study of everyday clinical practice. Diabetes Technol Ther 2008; 10: 121-127.

[23] Borah BJ, Darkow T, Bouchard J, et al. A comparison of insulin use, glycemic control, and health care costs with insulin detemir and insulin glargine in insulin-naive patients with type 2 diabetes. Clin Ther 2009; 31: 623-631.
[24] Gschwend MH, Aagren M, Valentine WJ. Cost-effectiveness of insulin detemir compared with neutral protamine Hagedorn insulin in patients with type 1 diabetes using a basal-bolus regimen in five European countries. J Med Econ 2009; 12: 114-123.

[25] Ridderstråle $M$, Jensen MM, Gjesing RP, et al. Cost-effectiveness of insulin detemir compared with NPH insulin in people with type 2 diabetes in Denmark, Finland, Norway, and Sweden. J Med Econ 2013; 16: 468-478.

[26] Valentine WJ, Erny-Albrecht KM, Ray JA, et al. Therapy conversion to insulin detemir among patients with type 2 diabetes treated with oral agents: a modeling study of cost-effectiveness in the United States. Adv Ther 2007; 24: 273-290.

[27] Yang L, Christensen T, Sun F, et al. Cost-effectiveness of switching patients with type 2 diabetes from insulin glargine to insulin detemir in Chinese setting: a health economic model based on the PREDICTIVE study. Value Health 2012; 15: S56-59.

[28] Home P, Baik SH, Gálvez GG, et al. An analysis of the cost-effectiveness of starting insulin detemir in insulin-naïve people with type 2 diabetes. Journal of medical economics 2015; 18: 230-240.

[29] Cardoso C, Ramirez de Arellano A, Prades M, et al. Cost-effectiveness Analysis of Insulin Detemir Compared to Neutral Protamine Hagedorn (NPH) in Patients with Type 1 and Type 2 Diabetes Mellitus in Portugal. JOURNAL OF DIABETES \& METABOLISM 2016; 7.

[30] Ji L, Zhang P, Weng J, et al. Observational Registry of Basal Insulin Treatment (ORBIT) in Patients with Type 2 Diabetes Uncontrolled by Oral Hypoglycemic Agents in China-Study Design and Baseline Characteristics. Diabetes Technol Ther 2015; 17: 735-744.

[31] Zheng Y, Wu J, Xie K. Incidence and cost of hypoglycemia episode in patients with type 2 diabetes mellitus. Chinese rural health service administration 2012; 32: 1195-1198.

[32] Zhou M, Astell-Burt T, Bi Y, et al. Geographical variation in diabetes prevalence and detection in china: multilevel spatial analysis of 98,058 adults. Diabetes Care 2015; 38: 72-81.

[33] National Bureau of Statistics of China. 2010 China population census http://www.stats.gov.cn/tjsj/pcsj/rkpc/6rp/indexch.htm. Accessed April 30, 2017.

[34] Kim SS, Kim IJ, Kim YK, et al. Duration of diabetes and effectiveness of insulin in the management of insulin-naïve Korean patients uncontrolled on oral antidiabetic drugs: a sub-analysis of the MOdaliTy of Insulin treatment eValuation (MOTIV) registry results. Acta Diabetol 2014; 51: 655-661.

[35] Yeaw J, Lee WC, Wolden ML, et al. Cost of Self-Monitoring of Blood Glucose in Canada among Patients on an Insulin Regimen for Diabetes. Diabetes Ther 2012; 3: 7.

[36] Yeaw J, Lee WC, Aagren M, et al. Cost of self-monitoring of blood glucose in the United States among patients on an insulin regimen for diabetes. J Manag Care Pharm 2012; 18: 21-32.

[37] Nilchaikovit T, Hill JM, Holland JC. The effects of culture on illness behavior and medical care. Asian and American differences. Gen Hosp Psychiatry 1993; 15: 41-50. 